\title{
PROTESTO AMBIENTAL E MUDANÇA SOCIAL NO REINO UNIDO*
}

Huw Beynon

\begin{abstract}
Os estudos sobre protesto e conflito no Reino Unido são dominados há décadas pelas pesquisas sobre o local de trabalho e as atividades organizadas por sindicatos. Em tempos recentes, o mais dramático desses conflitos foi a greve dos mineiros de 1984-19851. Apesar das esperanças existentes na época, esta greve terminou em derrota e, para muitos, passou a ser vista como a última das grandes lutas sindicais. Nos anos 80 e 90, o declínio dos antigos setores industriais combinou-se com a crescente insegurança econômica e com a legislação governamental, de tal maneira que enfraqueceu o poder das organizações de trabalhadores (ver, p. ex., Mcllroy 1997 e Beynon 1996). Não há como duvidar da importância dessas transformações. Seria um erro, contudo, imaginar que as estatísticas que mostram o declínio do número de greves implicam que a população está feliz e satisfeita. Seria igualmente equivocado supor que as organizações sindicais (apesar de terem um papel central e crítico) tenham sido o único locus de dissensão organizada no século XX. As mulheres sempre tenderam a se organizar vigorosamente fora das fábricas, e a relação entre as atividades com base na comunidade e aquelas centradas no local de trabalho tem sido objeto de considerável interesse por parte dos historiadores; recentemente, tornou-se uma preocupação também dos estudiosos do mundo contemporâneo.
\end{abstract}

\section{Novos padrões de protesto}

Algo que não havia sido previsto aconteceu na vida política da Grã-Bretanha nos anos 90. Depois de mais de uma década de thatcherismo, muitos supunham que o individualismo havia triunfado e que o mercado havia sido aceito de maneira generalizada como a base racional e justa da ação social. O slogan do final dos anos 50, "You've never had it so 
good" ("Nunca foi tão bom"), parecia até sutil quando comparado a "Loads of money" ("Montes de dinheiro"), o slogan dos anos 80. As desigualdades aumentavam, mas ninguém parecia se preocupar com isto. Os protestos ambientais que surgiram foram com freqüência interpretados sob essa ótica. Atitudes do tipo "No meu quintal, não" (NIMBYism - Not in my back yard) eram vistas como reflexos dos interesses dominantes de uma classe média barulhenta que desejava que, seja lá o que fosse ser despejado ou escavado, o fosse bem longe dali.

Mas tratava-se, evidentemente, de algo mais complexo. O Poll Tax* acarretou um sentimento genuíno de revolta, mesmo entre aqueles que dele se beneficiaram. Os protestos públicos fizeram com que o governo mudasse suas políticas e, efetivamente, puseram um fim à Sra. Thatcher. Em 1995, os jornais estavam repletos de matérias sobre o movimento de oposição à exportação para a França de carneiros e bezerros vivos. Os que participaram dos protestos (mulheres em sua maioria) tiveram tanto sucesso na realização de piquetes nos principais portos que os operadores de embarcações concordaram em não mais se envolverem nesse comércio. Em função disso, os exportadores passaram a usar aeroportos e pequenos portos que não tinham autorização para operar, levando seus grandes caminhões, cheios de jovens animais, para as ruas de pequenas cidades e vilas. Isso acarretou uma reação ainda mais militante, enchendo as ruas de manifestantes. Uma mulher morreu em meio aos protestos, e muitas pessoas queixaram-se asperamente de suas experiências nas mãos da polícia². O jornal The Observer anunciou que "A classe média tornou-se militante" (The Observer, 22/1/1995). O repórter deste jornal havia visitado Brightlingsea (um dos pequenos portos usados pelos exportadores) e presenciado a polícia forçando a passagem de caminhões cheios de carneiros e bezerros pelo meio de uma multidão de mulheres, crianças e aposentados que portavam cartazes, e observou:

“[...] os direitos dos animais, as tentativas do governo em Twyford Down de forçar a implementação de seu programa de estradas nos condados do nordeste da Inglaterra, as restrições aos ramblers ${ }^{* *}$ impostas pela Lei de Justiça

* N. T. - O imposto que ficou conhecido como Poll Tax foi introduzido no final dos anos 80 pelo governo Thatcher. Tratava-se de um imposto de valor igual para todas as pessoas, independentemente de sua renda. Houve manifestações contrárias em vários lugares na primavera de 1990.

${ }^{* *}$ N. T. - Ramblers, neste caso, são pessoas que fazem excursões pelas zonas rurais do interior do Reino Unido, e que defendem o direito de acesso ou de passagem em certas áreas (mesmo que sejam privadas), desde que não sejam cultivadas, quintais ou áreas com restrições de acesso justificadas há organizações que procuram garantir esse direito de acesso ou passagem por meio da legislação. 
Criminal [Criminal Justice Act], e até mesmo a tentativa de interromper a transmissão em ondas longas da Radio 4, trouxeram para as ruas um novo tipo de manifestante. A classe média está se tornando militante".

Dois anos mais tarde, o jornal The Economist chegou a uma conclusão semelhante, ao chamar a atenção para os protestos públicos contra a construção de uma estrada (Newbury bypass). O jornal citava Rob, um dos moradores locais que havia aderido ao protesto: "Acho que o movimento de ação direta vai começar a se diversificar cada vez mais [...] Fairmille [o local do protesto contra a estrada] é a universidade da ação direta. Nós estamos ensinando nossos métodos para gente do mundo inteiro" (The Economist, 25/1/1997).

Assim, de uma maneira curiosa e inesperada, as manifestações públicas passaram novamente a ser vistas por muitos como uma forma legítima de protesto. Naquele momento, o número de membros de grupos "verdes" era cinco vezes maior que o número de membros do Partido Trabalhista. Em pesquisas de opinião pública, de $80 \%$ a $90 \%$ das pessoas respondiam que as questões ambientais eram importantes para elas. Como observa Geoffrey Lean: "MORI* — verificando o que as pessoas realmente fazem em vez de apenas aquilo que elas dizem - descreve mais de um terço dos habitantes da Grã-Bretanha como 'ativistas ambientais'" (The Independent on Sunday, 14/7/1996:21).

Nos anos 80 e 90, "o meio ambiente" tornou-se uma questão política importante nas antigas áreas de mineração de carvão, trazendo o desenvolvimento da mineração a céu aberto para o centro das atenções.

\section{Mineração a céu aberto}

Há duas maneiras de extrair o carvão (e outros minérios) da terra: minas profundas (que envolvem um poço e mineiros trabalhando sob a superfície) e minas a céu aberto (que implicam raspar a superfície da terra, de modo a expor os veios de minério e criar uma grande vala aberta. A mineração a céu aberto está se tornando cada vez mais comum no mundo todo. Novas máquinas, maiores e mais sofisticadas, permitem que veios situados em superfícies cada vez mais profundas sejam explorados a partir da superfície. Minas gigantescas (como a de Carajás, no Pará) produzem

\footnotetext{
${ }^{*}$ N. T. - MORI é uma das maiores agências de pesquisa de opinião do Reino Unido.
} 
milhões de toneladas de minério a cada ano. Na Grã-Bretanha, essas minas a céu aberto são chamadas de opencast mines (nos Estados Unidos, o termo usado para a mineração a céu aberto é strip mining). Lá, elas são menores do que em Carajás, mas estão mais próximas de aglomerados populacionais. Por sua própria natureza, as minas a céu aberto são mais agressivas em relação ao meio ambiente local do que as minas profundas, e sua proximidade de cidades e vilas sempre causou certa preocupação.

Conseqüentemente, para abrir uma mina de superfície no Reino Unido é necessária uma autorização do Estado no plano local. Se esta autorização for negada, a empresa pode recorrer, e isso pode ocasionar uma Audiência Pública (public inquiry) ${ }^{*}$. Nessas Audiências as evidências são apresentadas diante de um inspetor público, e a decisão final requer a aprovação do ministro responsável pelo meio ambiente. As Audiências tornaram-se freqüentes na Grã-Bretanha nos anos 80, e as instâncias locais do Estado passaram a sofrer pressões para recusar as autorizações. As próprias Audiências eram espaços para discursos contrastantes, onde apresentavam seus argumentos as empresas de mineração, as instâncias locais do Estado e os moradores e seus aliados que se opunham às minas.

\section{Audiências públicas: dominação ou conflito?}

Asforth e outros autores argumentam que as Audiências Públicas podem ser vistas como "rituais simbólicos dentro de Estados modernos, teatros de poder que efetivamente 'fazem políticas', mas que fazem muitas outras coisas além disso" (Asforth 1980:3).

Esses rituais, efetivamente, elevam "o Estado" acima do resto da sociedade, colocando-o como uma arena na qual a verdade e a racionalidade operam em relação a interesses humanos. Vistas desse modo, as Audiências Públicas tornam-se: “Um teatro onde uma verdade central previamente aceita - o poder do Estado moderno - é ritualmente encenada diante de um público [...]. Os sujeitos podem falar livremente a respeito de seus interesses e serão ouvidos, e o poder do Estado aparece como um parceiro benevolente da Sociedade, na busca do bem comum" (Asforth 1980:9).

\footnotetext{
* N. T. - Optei por usar o termo "audiência" em vez de "inquérito" ou "inquirição", que em português me parecem ser mais usados no sentido de investigação de crimes ou irregularidades administrativas.
} 
Para o autor, as Audiências Públicas adotam "normas de decoro coerentes com a majestade do Estado". Tipicamente, essas normas "derivam da prática dos tribunais, especialmente no que diz respeito ao procedimento de perguntas e respostas". Na sua opinião, esses rituais e procedimentos funcionam como uma teia de aranha, que atrai os protestos para si e os reconstrói, pois eles "permitem uma expressão completa e livre de visões opostas [...] [e] desse modo, auxiliam na transformação de questões conflituosas, do âmbito das lutas políticas, em discursos de argumentação racional [...], permitindo que 'o Estado' fique acima da 'sociedade', incorporando o 'Bem Comum" (Asforth 1980:12).

Há inúmeros aspectos interessantes no trabalho de Asforth que têm muitos pontos de contato com a nossa própria pesquisa nas regiões de mineração. Contudo, é questionável a sua conclusão de que o envolvimento dos grupos de protesto nas Audiências Públicas faz pouco mais que assegurar a submissão desses grupos. No Reino Unido, no final da década de 80 e no início dos anos 90, o envolvimento público nas Audiências (quando conjugado a pressões políticas através de lobbies e a outras formas de protesto) conseguiu efetivamente resultados que muitas pessoas consideraram satisfatórios. Vários projetos de abrir minas a céu aberto foram arquivados, quando eles poderiam ter ido facilmente adiante. Há evidências importantes de que esse sucesso causou dificuldades reais para as empresas de mineração de carvão e que isso levou a uma reavaliação por parte do Departamento de Meio Ambiente, à qual se seguiram mudanças fundamentais nas regras que regulam o processo de autorização de abertura de minas a céu aberto. Essas regras, por sua vez, também passaram a ser contestadas e alteradas. Como resultado dos protestos, que muitas vezes foram orquestrados mediante a participação no próprio processo de Audiência Pública, foram alterados os limites do praticável e do possível.

Isto não quer dizer que muitos dos processos identificados por Asforth não ocorram de fato no sistema de Audiências Públicas. Em lugar disso, o que se pretende enfatizar aqui é o contexto prático (material) no qual essas características do poder de Estado são postas em cena. Nas Audiências que presenciamos, ficou claro que os moradores locais que protestavam queriam que suas vozes fossem ouvidas. Nesse sentido, a Audiência oferecia-lhes um foro onde podiam participar e ter sua vez de falar. Nas Audiências esses moradores passaram a ocupar uma posição específica, e muitos deles vieram a refletir sobre esse fato, tentando pensar as melhores maneiras para "fazer com que nossas idéias sejam entendidas". Contudo, eles ambicionavam mais que uma intervenção discursi- 
va. Antes de mais nada, queriam assegurar que as áreas próximas ao local onde viviam não se tornassem minas a céu aberto. Havia uma forte motivação estética e instrumental para o seu envolvimento.

Motivação instrumental era o que não faltava às empresas de mineração de carvão. Quando as decisões começaram a desfavorecer essas empresas no final dos anos 80 e início dos 90, elas passaram a pressionar o Departamento de Meio Ambiente para que as regras fossem mudadas. Reclamavam que o sistema de Audiências Públicas era muito caro, demorado e excessivamente democrático, permitindo que vozes demais fossem ouvidas e espaço demais ocupado. As empresas desenvolveram táticas cujo objetivo era contornar as regras e induzir a "oposição" a colocar-se em situações difíceis. "Não deixe que os moradores locais levem você para o buraco" era a mensagem que queriam passar, associada a uma forma de abordagem mais agressiva com relação aos manifestantes. O resultado disso foi que a indústria carvoeira e a CoalPro (uma organização guarda-chuva que reunia os interesses das empresas de carvão) tornaram-se elementos centrais de um forte lobby antiambientalista. Por um lado, tentaram produzir pesquisas científicas que conseguissem "provar" a falsidade das alegações de que a mineração a céu aberto e o uso do carvão de modo geral tinham impactos negativos sobre o meio ambiente. Contestaram a relação entre chuva ácida e emissões de dióxido de enxofre pelas usinas termoelétricas a carvão. Argumentaram persistentemente que os efeitos ambientais da mineração a céu aberto eram positivos. Insistiram em afirmar, com exagero, a qualidade do carvão produzido por métodos de mineração a céu aberto e propagandearam essa visão, com impacto considerável. Ao mesmo tempo, essas empresas atacavam incessantemente as credenciais e motivos do lobby ambientalista. Tornou-se comum descrever ativistas ambientais como "bichas" e referirse a todo o argumento ambientalista como vagamente afeminado, algo que "homens de verdade" não deveriam levar a sério. Esse tipo de linguagem era usado principalmente nas salas das comissões e nas conversas nos bares e restaurantes. Publicamente, a indústria também manteve um ataque quase incessante sobre aquilo que passou a ser conhecido como o lobby ambientalista. Colin Goldfrey, diretor de Desenvolvimento de Mercado da mineradora RJB, usou essa expressão em seu discurso para a Conferência Anual da Campanha das Comunidades Carvoeiras, em 19 de setembro de 1996. Em sua opinião, esse lobby era uma ameaça ao conjunto da indústria carvoeira, e era necessário reduzir a sua influência ${ }^{3}$.

Esses ataques retóricos conjugavam-se a uma tentativa organizada de pressionar financeiramente as autoridades locais. Tal abordagem 
envolvia tanto a "vara" como a "cenoura" * As autoridades responsáveis pela aprovação de projetos na área de mineração eram informadas pelas empresas que uma rejeição do mesmo iria certamente levá-las a entrar com um recurso e à inevitável Audiência Pública. Essas Audiências envolviam custos financeiros reais para as autoridades, agravados pelo fato de que se o recurso fosse vitorioso, a parte entrante iria demandar, com sucesso, ressarcimento dos custos por parte da autoridade local. As empresas de carvão procuravam deixar cada vez mais claro que elas iriam "entrar com tudo", caso o seu pedido de autorização fosse recusado. Os riscos eram, com freqüência, suficientemente grandes para fazer com que as autoridades locais fingissem não ver os protestos dos moradores.

Esse processo se tornava ainda mais complexo com a oferta da "cenoura". As empresas ofereciam regularmente recursos financeiros para as autoridades locais como pagamento por algum benefício público. Tais recursos eram apresentados como planning gain, um benefício que decorria diretamente, ainda que não intencionalmente, do desenvolvimento das atividades de mineração. Isso era interpretado de forma cada vez mais abrangente, e foi-nos descrito várias vezes por planejadores locais como "um suborno". Em muitos dos distritos carvoeiros, o assunto era objeto de consideráveis disputas políticas e discussões públicas. A polêmica a respeito do planning gain tornou evidente o peso cada vez maior que o dinheiro tinha nas decisões de planejamento nas regiões onde a insegurança econômica era crescente. Nesses lugares, as empresas de carvão ampliavam seu poder porque havia uma demanda por benefícios e, fora a Loteria, elas pareciam ser a única fonte provável de recursos.

Assim, o papel do Estado no planejamento pode ser visto como ocupando um espaço discursivo através do qual o uso do solo nos distritos carvoeiros é regulado. Tal regulação, contudo, está relacionada a conflitos reais por interesses materiais, e tornou-se claro que as empresas mineradoras de carvão só estavam inclinadas a aceitar discussões, argumentações e discordâncias até certo ponto. Para obter a autorização de mineração do Estado, estavam dispostas a contornar regras, pressionar por

\footnotetext{
* N. T. - A expressão "the stick and the carrot", literalmente "a vara e a cenoura", remete à imagem de formas de lidar com cavalos, e indica nesse caso a combinação de ações que visam ameaçar ou agredir (a "vara") e ações que visam atrair ou cooptar (a "cenoura"). Em outros casos, a expressão pode estar referida à imagem de uma cenoura amarrada a uma vara que, por sua vez está presa a um cavalo de modo que a cenoura esteja sempre à sua frente, sem que ele jamais consiga alcançá-la.
} 
mudanças nas mesmas e constranger incessantemente os responsáveis pelas decisões - o que não passou despercebido aos planejadores e representantes locais do Estado, como tampouco aos manifestantes locais que se opunham às empresas.

\section{Padrões de protesto e oposição}

Uma das dinâmicas críticas de transformação social nas duas últimas décadas do século relaciona-se com as mudanças nos padrões de protesto e nas formas de política de oposição. Conforme o Estado se retira do campo dos interesses materiais, deixando as decisões a cargo "do mercado", a ação política passa a ser realizada fora dos principais canais institucionais. Esse processo se acelera na medida em que declina o prestígio dos políticos como categoria. De acordo com Paul Byrne, essa metamorfose ocasionou uma "revolução na forma de conduzir a política britânica e na sua prática":

"A maioria das pessoas, durante a maior parte do tempo, continua a participar da política apenas de forma esporádica, e a política continua a ocupar uma posição relativamente baixa na escala de prioridades da vida cotidiana. O que mudou, contudo, é que para muitos dentre aqueles que estão ativamente interessados, a política não significa mais apenas a participação em partidos nacionais, na política local e em grupos de interesse convencionais, tais como os sindicatos" (Byrne 1997:6).

Essa tem sido a experiência nas áreas de mineração de carvão, como se pode ver na Tabela 1. Durante décadas, as questões relativas à mineração a céu aberto foram resolvidas no âmbito das burocracias locais e do Conselho Nacional do Carvão (National Coal Board). O Sindicato Nacional dos Mineiros (National Union of Mineworkers - NUM) preocupava-se, fundamentalmente, com questões de produção e de direitos trabalhistas relativas aos seus membros que atuavam nas minas profundas. A mineração a céu aberto era vista como uma questão marginal em termos da indústria e irrelevante para os interesses dos mineiros que trabalhavam no subsolo.

Nessa época, o NUM aceitava a visão da empresa estatal de que uma certa quantidade de carvão obtido a céu aberto era necessária para "adoçar" o carvão retirado das minas profundas (especialmente carvão de coque), e os protestos isolados de alguns indivíduos eram em grande 
medida ignorados. O fracasso do Plano do Carvão e o fechamento das minas profundas transformaram dramaticamente a situação. Os grupos de ação locais deixaram de ver-se como ameaça aos empregos nas minas profundas; na verdade, passaram a sentir que estavam ajudando a salvar esses empregos. Ao se defrontarem com organizações burocráticas locais que se mostravam recalcitrantes e com regulamentações formais de planejamento, esses grupos se informaram sobre a legislação de planejamento. Tal conhecimento aumentou sua capacidade de fazer oposição, o que foi reforçado pelos contatos com os ativistas e simpatizantes do NUM, que também possuíam conhecimentos sobre a indústria do carvão, sobre o próprio carvão e sobre os mercado de energia.

Essa foi a marca de um movimento reformista dinâmico em que alianças locais conseguiram reunir novos tipos de evidências e usá-las nas Audiências Públicas. Elas também foram capazes de aproveitar a influência política dos sindicatos nesses distritos. Foi uma aliança nova e poderosa que obteve ganhos reais.

Autores que escreveram sobre os "novos movimentos sociais" observaram o surgimento de uma "militância crescente" em grupos (como o Greenpeace) vinculados à proteção do meio ambiente. Verificaram, também, tendências a dissensões e rachas internos (ver, p. ex., Byrne 1997) Esse fenômeno ocorreu igualmente nos movimentos de protesto relacionados à mineração a céu aberto. As estratégias das empresas colaboraram para que isso acontecesse. O sucesso obtido por conta da utilização de táticas convencionais de lobby e de apresentação de evidências nos Inquéritos, passou a ser visto, na melhor das hipóteses, como parcial. "Para que serve argumentar se ninguém dá ouvidos aos argumentos?" - esse foi um sentimento que ganhou corpo nas áreas de mineração de carvão, e passou a ser representado em diferentes formas de ação organizada. 
Tabela 1: Formas de resposta local organizada à mineração a céu aberto.

\begin{tabular}{l|l|l|l}
\hline & Partidos políticos & Grupos de ação locais & Grupos de oposição \\
\hline $\begin{array}{l}\text { 1) Forma } \\
\text { organizativa }\end{array}$ & $\begin{array}{l}\text { Burocracia formal do } \\
\text { Estado local, das em- } \\
\text { presas mineradoras e } \\
\text { dos sindicatos. }\end{array}$ & $\begin{array}{l}\text { Bases locais, com ali- } \\
\text { anças informais com } \\
\text { o Estado local, grupos } \\
\text { ambientalistas e al- } \\
\text { guns sindicatos locais. }\end{array}$ & $\begin{array}{l}\text { Grupos de ativistas } \\
\text { independentes, com } \\
\text { bases locais, redes } \\
\text { nacionais. }\end{array}$ \\
\hline $\begin{array}{l}\text { 2) Forma } \\
\text { de ação }\end{array}$ & $\begin{array}{l}\text { Reclamações individu- } \\
\text { ais e ação legal; não } \\
\text { há oposição formaliza- } \\
\text { da - "Não há nada } \\
\text { que possa ser feito". }\end{array}$ & $\begin{array}{l}\text { Pressão por meio de } \\
\text { lobbies sobre os mem- } \\
\text { delegacias sindicais, } \\
\text { diretórios partidários e } \\
\text { comissões locais do go- } \\
\text { verno; participação nas }\end{array}$ & $\begin{array}{l}\text { Ação direta através de } \\
\text { formas de ocupação, } \\
\text { bloqueios e manifes- } \\
\text { tações. }\end{array}$ \\
\hline $\begin{array}{l}\text { 4) Ideologiâncias Públicas. } \\
\text { 3) Discurso }\end{array}$ & $\begin{array}{l}\text { Produtivismo progres- } \\
\text { sista: "precisamos do } \\
\text { carvão"; planos nacio- } \\
\text { nais. }\end{array}$ & $\begin{array}{l}\text { Ceticismo ambienta- } \\
\text { lista: "Será que preci- } \\
\text { samos mesmo do car- } \\
\text { vão?". }\end{array}$ & $\begin{array}{l}\text { Ambientalismo mili- } \\
\text { tante: "nós não preci- } \\
\text { samos do carvão"; } \\
\text { questões locais. }\end{array}$ \\
\hline
\end{tabular}

Em 1995, o jornal The Guardian descreveu: "à luz de lamparinas e de capacetes de mineração, 50 pessoas de comunidades de mineiros ex-mineiros, membros de conselhos sindicais e ativistas ambientais cavavam, em busca de carvão, usando pás e picaretas. Em certos locais, já haviam cavado cerca de trinta centímetros".

O grupo havia pedido autorização para explorar minérios nesse lugar e essa era a sua "visita preliminar ao local". Na opinião de Steve Parry, "aqui estamos diante de uma das vistas mais belas da Grã-Bretanha, mas comunidades inteiras estão dependendo do seguro-desemprego. Por toda a Grã-Bretanha lugares tão lindos como este estão sendo destruídos" (The Guardian, 11/11/1995).

O grupo repetiu a ação em 1997; dessa vez na casa de Richard Budge, proprietário da mineradora RJB. O jornal The Times relatou:

"A senhora Scargill, 52, estava entre os cinco manifestantes presos às cinco da manhã em Wiseton, Nottinghamshire, acusada de perturbação da ordem. Mais tarde ela voltou ao local, a cerca de oitocentos metros da propriedade do sr. Budge, e foi novamente detida. Depois de ser solta pela segunda vez, 
mais uma vez sem que fosse formalizada uma acusação, ela disse: 'Eu estava lá como membro do grupo de campanha No Opencast [ "Não à Mineração a Céu Aberto"], e não como esposa de Arthur Scargill, e eu estava lá em protesto às políticas de Budge [...]. Ele não sabe o que é acordar de manhã e dar de cara com uma mina a céu aberto'" (The Times, 10/5/1997:9).

Essa política de "demonstração", ao transferir experiências de um lugar para outro, teve grande efeito visual. Incentivou diferentes pessoas a imaginarem novas maneiras de organizar-se e comunicar-se. Em Derbyshire, os participantes da campanha contra uma mina a céu aberto proposta por H.J. Banks despejaram uma grande quantidade de carvão em Chatsworth House, residência do dono da área, o duque de Devonshire. Hugh Ellis, do grupo de manifestantes, observou: "Vamos ver se o duque gosta de ter uma pilha de carvão na porta de sua casa". Ele discordou da idéia de que uma mina a céu aberto iria gerar os empregos que a região necessitava. A sua opinião era a seguinte: "Nós sentimos que Chatsworth está nos vendendo. O duque é riquíssimo e ganha muito dinheiro com a sua propriedade de Chatsworth House. Mas essa área é uma região rural de alta qualidade, que as pessoas podem desfrutar sem gastar nada. Por que transformá-la em mais uma área industrial?"

A sua companheira de campanha, Ann Syrett, havia falado com o duque. "Ele nos disse que nós éramos muito egoístas e que deveríamos estar felizes por causa dos empregos que seriam criados na região. Mas eu acho que ele não está bem informado" (Yorkshire Post, 8/7/1996).

O contraste entre evidências organizadas, como as apresentadas nas Audiências Públicas, e incursões noturnas em casas de ministros é bem ilustrativo. Marca um movimento, bem captado por Pakulski, do campo discursivo para o demonstrativo. De acordo com ele, os novos movimentos sociais costumam: "Lançar mão de exemplos em lugar de argumentos discursivos; eles buscam a moralização da política através da ação, a reforma da vida social e a mudança das orientações individuais, tudo em nome de valores e princípios que eles acreditam estar sendo negligenciados, distorcidos ou corrompidos" (Pakulski 1991:42).

Nas antigas áreas de mineração, essa tendência foi expressiva, e os sentimentos a ela associados foram bem assimilados pelas atividades públicas de grupos como o No Opencast. Ao viajarmos por essa região nos anos 90, fomos levados a perceber o apoio crescente às idéias de ação direta. As pessoas - especialmente os jovens e os velhos - deixaram bem claro que para deterem a criação de minas a céu aberto estavam preparadas para deitar-se diante das retroescavadeiras, invadir proprieda- 
des e manifestar-se de qualquer maneira que parecesse viável. Quando questionados sobre os aspectos legais, deixaram claro que os tribunais de justiça e as noções de prisão e punição não têm mais o peso de sanções normativas que costumavam ter nesses distritos. Aqui, a sanção da comunidade local tem todo poder: "é tudo o que nos restou". Esta é uma expressão muito ouvida, e quando ela está respaldada em uma forte campanha local, torna-se uma poderosa força de radicalização. Isso levanta muitas questões quanto à natureza social dos protestos contra a mineração a céu aberto no contexto dos movimentos sociais ambientalistas.

\section{Composição social}

As discussões a respeito desses novos tipos de movimentos políticos costumam associá-los à emergência de uma "nova classe" composta por pessoas escolarizadas, vinculadas a profissões "humanistas". Dado o seu conhecimento formal, essas pessoas teriam compreendido a natureza dos problemas ambientais e o risco potencial de danos severos ao meio ambiente e aos ecossistemas locais. Esse grupo é visto - em função de sua socialização inicial, reforçada no âmbito de suas profissões — como tendo valores fortemente altruísticos, que levariam seus membros à participação política. Para Offe (1985) e outros, essas pessoas formam a espinha dorsal dos novos movimentos sociais que trouxeram questões específicas, como a paz e o meio ambiente, para o primeiro plano da vida política.

Os protestos em torno da mineração a céu aberto e seu impacto sobre o meio ambiente local envolveram, de fato, membros dessa "nova classe". Jovens advogados, professores e estudantes de pós-graduação participavam, mas eles não predominavam. Um ativista como Desmond Napier, que teve um papel-chave no Vale de Derwent, em West Durham, era um empresário independente. Por outro lado, muitas pessoas da área de planejamento acabaram apoiando os protestos, mais em função de noções de planejamento racional do que por profundas convicções altruísticas. O envolvimento da "classe média" ia, portanto, além dessa "nova classe". Em certos casos, incluía até mesmo a aristocracia. Em Fife, Andrew Wemyss, um proprietário de terras local, teve um papel fundamental para evitar a criação de minas a céu aberto.

Talvez o fato mais importante seja o de que muitas pessoas mais pobres, da classe trabalhadora, também se envolveram nesses protestos. Isto é reflexo, evidentemente, da composição social desses antigos distri- 
tos mineiros. John Smith qualificou o distrito eleitoral de Tony Blair em Sedgefield, County Durham, como uma mistura de "cerveja escura e vinho bordô", o que serve para evidenciar, uma vez mais, a especificidade desses locais e da história de sua indústria rural. O passado manteve uma forte influência sobre as lealdades e sobre a forma de ver o mundo dessas pessoas. Ele foi freqüentemente evocado à medida que as minas a céu aberto se difundiam e se voltava a utilizar veios de carvão que antes haviam sido parcialmente explorados pelos mineiros que trabalhavam em minas profundas. O resultado é que os grupos de protesto contra a mineração a céu aberto nessas áreas aproveitaram as experiências dos mineiros desempregados e dos sindicalistas. Steve Parry do grupo No Opencast fez uma observação interessante a esse respeito:

\footnotetext{
“Acho que não há nenhuma outra questão 'verde' que seja tão claramente vinculada às reivindicações tradicionais dos sindicalistas, tanto em termos de empregos, salários, saúde e segurança, como também em termos da cultura das comunidades mineiras. Os mineiros que passavam dias e noites embaixo do chão provavelmente apreciam mais do que qualquer outra pessoa o ambiente natural e o ar puro. Isso é parte da vida da comunidade mineira" (The Guardian: Weekend, 6/9/1997).
}

A experiência da greve dos mineiros de 1984-85 também foi importante. A mineração a céu aberto foi identificada como questão sindical no curso dessa disputa. Personagens que estiveram envolvidos nos grupos locais de apoio aos mineiros e em organizações como Women Against Pit Closures (Mulheres Contra o Fechamento de Minas Profundas) travaram contato com as discussões mais gerais sobre essa forma de mineração. Nos anos que se seguiram, muitos deles usaram esse conhecimento ao se envolverem em algum grupo local de protesto. A ligação entre elementos da "nova classe" e pessoas da classe trabalhadora e formas mais tradicionais de organização como os sindicatos talvez seja uma característica específica e peculiar dessa forma de protesto. Tal peculiaridade, contudo, não deve ser exagerada. Em um levantamento sobre participação política, realizado em 1984, Geraint Parry e seus colegas descobriram que os movimentos pacifistas e ambientalistas tinham seu principal apoio, sobretudo, em dois grupos da sociedade britânica. Em primeiro lugar, havia "aquelas pessoas com alto nível de instrução, mas com níveis médios ou baixos de recursos materiais - ou seja, os menos bem colocados dentre os que tinham instrução superior". Esses indivíduos se combinavam com "uma falange forte formada por pessoas com poucos recur- 
sos e pouca qualificação educacional, tanto trabalhadores pobres como desempregados" (Parry, Moyser e Day 1992:215).

Essa também era a situação nos distritos carvoeiros, onde em muitos casos predominava essa "falange forte". As experiências e os recursos daqueles que tiveram um papel ativo no sindicalismo e em outras formas de protesto social ajudaram a formar um agrupamento poderoso. Ainda que nesses grupos a tendência predominante fosse que os homens ocupassem as posições de liderança, um número significativo de mulheres participava, e elas articulavam fortes argumentos relacionados com a comunidade local e sua segurança.

\section{Novos conhecimentos}

Essas retificações ao argumento da "nova classe" podem ser ampliadas. O ativismo político nos distritos de mineração de carvão aponta para as maneiras pelas quais pessoas com pouca educação formal podem aprender sobre questões sociais profundas e chegar a uma compreensão a respeito delas. Com relação a isso, as delegacias sindicais e os programas educacionais dos sindicatos são fontes de "conhecimento leigo" que têm sido subestimadas (ver, p. ex., McIlroy e Westwood 1993). Suspeitamos que os processos mais informais também vêm sendo menosprezados. Os grupos locais de protesto, uma vez estabelecidos, tornam-se dramáticos "espaços de aprendizagem", à medida que os ativistas aprendem (em larga medida mediante "tentativas e erros") com aqueles que já sabiam algumas coisas e depois com aqueles que sabem bastante. Panfletos e documentos passam a ser distribuídos e a chegada da Internet acelera esse processo de transmissão de conhecimentos.

Tais informações foram utilizadas de diversas maneiras nas tentativas de proteger o "meio ambiente local". Nossas pesquisas nas áreas de mineração de carvão confirmam essas observações e as ampliam. A maioria das pessoas com as quais conversamos foi levada a aderir aos grupos de protesto em decorrência de alguma iniciativa particular, no momento em que surgiu algum pedido de autorização para instalação de uma mina a céu aberto. Ao avaliar sua oposição, as pessoas recorriam a vários argumentos, muitos dos quais relacionados às particularidades do contexto local. Eram comuns as alusões a questões gerais relativas ao futuro do planeta, mas as questões críticas eram as locais. Nesse sentido, os resultados de nossa pesquisa são coerentes com as observações de Kate Burningham e Martin O'Brien a respeito das percepções e valores daqueles 
que participam dos protestos contra a construção de estradas. Eles argumentam que, nesse caso, as pessoas geralmente empregam noções relacionadas ao "meio ambiente" de forma instrumental, ajustando-as ao contexto local. De acordo com esses autores, "no plano local o compromisso com o meio ambiente é regularmente traduzido de modo a se adequar às condições locais". Assim,

"Há divergências consideráveis entre as pessoas, em todas as situações, a respeito do que exatamente quer dizer 'o meio ambiente'. Isto fica bem ilustrado se observarmos conflitos relacionados ao planejamento nos quais indivíduos e grupos atribuem diferentes valores ambientais a determinadas áreas, afirmando que algumas áreas são 'o meio ambiente' e merecem ser protegidas, enquanto outras áreas não. Essas atribuições de valor ambiental são informadas por uma complexa rede de compromissos pessoais, sociais e políticos e não apenas por considerações ambientais formais" (Burningham e O'Brien 1994:919-920).

Esse processo de "transferência ao local" também ocorreu nas áreas de mineração de carvão, mas de modo mais complexo. Nesse caso, noções a respeito do ambiente e da paisagem locais também foram interpretadas de acordo com parâmetros humanistas. Mediante referência a experiências passadas, bem como a questões concretas, tais como barulho, poeira e saúde, constituíram-se noções a respeito do meio ambiente local de modo a respaldar a postura de oposição. Sem dúvida, havia fortes lógicas instrumentais em operação: as pessoas não queriam minas a céu aberto nas vizinhanças de suas casas. No entanto, existiam também noções abstratas, de ordem estética, envolvidas na forma como os indivíduos construíam o "meio ambiente local". Não era uma questão apenas de valor da propriedade e desejo de tranqüilidade. Freqüentemente, surpreendiamo-nos com a capacidade de pessoas sem educação formal de apreender e ampliar noções abstratas relativas ao meio ambiente humano e a comunidades sustentáveis, conforme elas iam conversando nos bares e nos clubes, nas cozinhas e nos salões onde eram feitas as reuniões, bem como nas Audiências Públicas.

Geralmente, essas conversas faziam referência às experiências diretas das pessoas na localidade. A apresentação desses relatos nas Audiências Públicas contrastava fortemente com as evidências apresentadas pelos "especialistas". Proferidos em dialeto local, os relatos enfatizavam as transformações da vida local: 
“De modo geral, o senso de identidade existente nas aldeias foi destruído, juntamente com o tecido social das comunidades [...]. O declínio da mineração de carvão veio de mãos dadas com o surgimento da mineração de carvão a céu aberto [...]. O Mapa 2 mostra a escala da mineração a céu aberto nas cercanias de Tow Law [...]. Nós estamos sendo obrigados a conviver com transtornos, como muito barulho e poeira, vibrações causadas pelas explosões, tráfego pesado em frente às nossas casas, e luzes fortes dos refletores invadindo os nossos quartos de dormir. A mineração a céu aberto destruiu boa parte do meio ambiente natural da região. Muitos animais silvestres, como raposas, gansos, patos, coelhos e texugos, além de flores, árvores e arbustos silvestres, desapareceram da região ou foram destruídos [...] não bastasse tudo isso, uma criança afogou-se em uma das lagoas na mina de Red Barns, logo que ela foi aberta há quinze anos [...]. Os supostos benefícios para a região não chegaram a acontecer. Em Billy Row, Sunnyside e Stanley Hill, não há mais do que cinco pessoas trabalhando nas minas a céu aberto. Como aconteceu em outros lugares, a maioria das pessoas empregadas nas minas a céu aberto é de fora" (Evidence, Billingside Opencast Public Inquiry 1987).

Assim, as Audiências Públicas tornaram-se, com freqüência, foros nos quais diferentes tipos de conhecimentos competiam uns com os outros. Elas também revelavam idéias distintas de justiça. Um grupo de manifestantes, por exemplo, que conseguiu desafiar com sucesso a empresa de carvão, ficou exasperado ao saber que a empresa pretendia entrar novamente com um pedido de autorização. O líder do grupo escreveu na imprensa local:

“Eu sempre acreditei que nós na Grã-Bretanha vivíamos em uma sociedade justa e democrática, mas a atitude do Sr. Palmer contribui bastante para desfazer essa crença. É uma prova clara [...] de que ele não se importa com a opinião das pessoas, dos conselhos locais ou mesmo do governo central. Tudo o que posso dizer ao Sr. Palmer e seus comparsas é que sua atitude de desprezo com relação às opiniões das pessoas em geral e da sociedade como um todo só reforça a nossa convicção, e tenho certeza que a de outros grupos de ação também, no sentido de continuar a representar a voz da maioria" (Nottingham Evening Post, 21/5/1990:4).

Com atitudes como essa, e utilizando noções como "necessidade" e "cobiça", os grupos de protesto passaram, cada vez mais, a argumentar contra a mineração a céu aberto em si, e não mais simplesmente nos contextos locais. 
Os processos em que se observou essa mistura de interesses locais com um programa geral de oposição eram de caráter político. No final dos anos 80, antes de o governo mudar as regras de autorização, os grupos de protesto locais e as autoridades de planejamento do setor mineral pareciam estar razoavelmente satisfeitos. Naquele momento, acreditavase que haveria objeções razoáveis e que a mineração a céu aberto se restringiria a um número aceitável de minas, a maioria delas situada em terras abandonadas em antigas áreas de mineração de carvão. Mas logo a seguir a situação transformou-se. As mudanças nas regras e no comportamento das empresas intensificaram a oposição local, que ganhou ainda mais fôlego com a crise que afetou a indústria carvoeira em 1992, e que deixou muitos dos antigos distritos mineiros sem minas profundas. A privatização da indústria de carvão exacerbou o sentimento de traição, e também levou a um aumento do número de envolvidos nos movimentos de oposição, pois muitos ex-mineiros e suas famílias foram aderindo à oposição e aos protestos. Nesse momento, a sensação de "bloqueio" na participação em mecanismos formais da política, já observada com relação a outros tipos de protesto $^{5}$, também impulsionou a adesão a grupos de protesto contra a mineração a céu aberto.

\section{Uma nova política de meio ambiente?}

Em sua avaliação da vida política na Grã-Bretanha ao final do século, Larry Eliot argumenta que o protesto ambiental se tornou "o ponto focal da oposição política de base na Grã-Bretanha". Em sua opinião: "Twyford Down e Newbury substituíram o depósito de carvão de coque de Saltney e Orgreave como marcos da luta entre o Estado e seus oponentes" (The Guardian, 20/1/1997).

Na oposição, o Partido Trabalhista tentou catalisar esse descontentamento e inseri-lo em sua estratégia eleitoral. Joan Ruddock, como "Ministro de Oposição" [Shadow Minister] para a Proteção Ambiental emitiu uma nota sobre a mineração a céu aberto, observando que "investigações independentes invariavelmente concluem que o efeito sobre as comunidades locais e sobre o meio ambiente pode ser extremamente grave". Esta nota deixava claro que, no governo, os trabalhistas iriam dar "maior ênfase às considerações ambientais" (Environmental Protection Briefing: Opencast Mining, 13/8/1995). Esse sentimento foi reafirmado por Frank Dobson, que se referiu à mineração a céu aberto como uma "megaestupidez ambiental" e às minas como "maus vizinhos". Para mui- 
tas pessoas, isso abriu a emocionante perspectiva de um novo governo trabalhista comprometido com a resolução de muitas das tensões entre a política "vermelha" e a "verde", promovendo uma estratégia de abertura associada a uma crescente consciência ambiental. Mas não seria fácil a tarefa de alcançar um equilíbrio dinâmico entre questões como emprego e crescimento econômico, por um lado, e meio ambiente e sustentabilidade local, por outro. Ao final do seu primeiro ano de mandato, a estratégia do novo governo poderia ser descrita como "cautelosa".

Fica claro, contudo, que essas questões não vão desaparecer no futuro próximo. A mudança na percepção pública da mineração a céu aberto pode ser ilustrada pelo fato de que hoje, na Grã-Bretanha, há uma considerável resistência aos grandes projetos de engenharia civil, sendo que houve época em que havia uma aceitação e aquiescência generalizadas. Essa mudança na atitude do público foi influenciada por vários fatores. $\mathrm{O}$ desemprego é um, e associado a ele o número cada vez maior de pessoas que passam boa parte de seu tempo em casa. Assim, conforme as minas profundas foram fechando, as pessoas (muitas delas mineiros desempregados) passaram a questionar a própria idéia da necessidade de ampliar a mineração de carvão. Aconteceu o mesmo com relação a estradas e aeroportos e com a exportação de animais vivos: as pessoas passaram a questionar a "necessidade" dessas atividades, vistas por elas como dispensáveis e destrutivas.

A privatização da indústria foi outro fator. Ainda que as indústrias nacionalizadas e os serviços públicos não fossem universalmente vistos como algo a ser admirado e defendido, eles podiam ao menos contar com um certo nível de tolerância por parte do público. Um exemplo disso é o fato de que quando a empresa pública de água pediu que os usuários racionassem o consumo durante períodos de seca, houve colaboração: o consumo de água diminuiu. Mas depois da privatização isso não mais aconteceu. Os executivos mais graduados das empresas privatizadas aumentaram consideravelmente seus salários. Conseqüentemente, passaram a ser identificados como "tubarões" (fat cats), e não contavam com a simpatia ou respeito públicos. Quando pediram à população que reduzisse o consumo de água, houve muita revolta em algumas regiões. No verão quente de 1996, o consumo de água aumentou em vários lugares, apesar dos pedidos públicos de moderação. As pessoas expressaram sentimentos semelhantes a respeito dos recursos financeiros envolvidos nos contratos relativos a estradas, comparando a renda local e a renda das empresas de engenharia. Houve um processo similar nas áreas de mineração de carvão. Uma vez privatizadas as empresas, a tolerância que os 
indivíduos em certo momento expressaram com relação à invasão de suas vidas pela mineração de superfície parece ter evaporado. Eles passaram a hostilizar as empresas de carvão e a protestar contra as suas atividades.

Nesse sentido, essas ações e atitudes podem ser vistas como refletindo mudanças mais gerais na sociedade. Ainda que as circunstâncias sejam menos opressivas, as reações dessas pessoas podem ser comparadas às dos "povos da floresta" no Brasil, que protestam contra usinas hidrelétricas e outros grandes projetos de engenharia. Há no mundo inteiro muitos exemplos de grupos que desafiam fortemente o direito de Estados e grandes empresas invadirem e alterarem a estrutura física de seu ambiente local. Nesse processo, "o meio ambiente" aparece como uma "coda" através da qual os interesses e preocupações gerais das pessoas podem ser expressos. A importância de movimentos como esses deve aumentar no próximo século. Estudos detalhados de como eles surgem e como refletem mudanças de percepção na sociedade civil são bastante relevantes e representam um amplo campo para a antropologia comparativa.

Tradução: John Comerford

Revisão Técnica: Carlos Fausto
Recebido em 22 de setembro de 1998

Aprovado em 25 de novembro de 1998

Huw Beynon é professor de Sociologia na University of Manchester, GrãBretanha. É autor dos livros Masters and Servants: Class and Patronage in the Making of a Labour Organization (1994), com Terry Austrin, e Working for Ford (1975), traduzido para o português em 1995. 


\section{Notas}

* Este trabalho está baseado em pesquisas realizadas na Grã-Bretanha ao longo dos últimos dez anos em conjunto com Andrew Cox e Ray Hudson.

1 Relatos desta greve podem ser encontrados em Beynon (1985).

2 Os relatos dessas pessoas foram semelhantes em muitos aspectos aos dos mineiros de carvão em greve nos anos 1984-1985. Naquela greve, por exemplo, os mineiros contaram que a polícia os escarnecia e que os policiais os provocavam acenando com notas de dinheiro e ridicularizando a sua pobreza. Dez anos mais tarde, os manifestantes revoltaram-se com o modo como os policiais faziam gestos obscenos e imitavam os sons dos animais.

3 Esses desenvolvimentos na indústria carvoeira do Reino Unido podem ser vistos como parte de um padrão mais geral, no qual os grupos empresariais partiram para o "revide" contra os movimentos ambientalistas nos Estados Unidos e na Europa. Ver, p. ex., Rowell (1996).

4 Ao notar essa tendência, Byrne observa que: "Virtualmente, todos os partidos políticos formados a partir dos movimentos ambientalistas experimentaram sérias dissensões internas em torno das táticas e direções a serem seguidas" (:22).

5 Ver a discussão de Scott (1990). 


\section{Referências bibliográficas}

ASFORTH, A. 1980. "Reckoning Schemes of Legitimation: On Comissions of Inquiry as Power/Knowledge Forms". Journal of Historical Sociology, 3(1): 1-21.

BEYNON, Huw (ed.). 1985. Digging Deeper. London: Verso.

_.1996. "A Destruição da Classe Operária Inglesa?" . Revista Brasileira de Ciências Sociais, 39(2):253-279.

BURNINGHAM, Kate e O'BRIEN, Martin. 1994. "Global Environmental Values and Local Contexts of Action". Sociology, 28(4):919-920.

BYRNE, Paul. 1997. Social Movements in Britain. London: Routledge.

MCILROY, John. 1997. "O Inverno do Sindicalismo". In: R. Antunes (ed.), Neoliberalismo, Trabalho e Sindicatos. São Paulo: Boitempo Editorial. pp. 39-70.

_ e WESTWOOD, Sallie. 1993. Border County: Raymond Williams in Adult Education. Leicester: National Institute of Adult and Continuing Education.

OFFE, C. 1985. "New Social Movements: Challenging the Boundaries of Institutional Politics". Social Research, 52:817-868.

PAKULSKI, J. 1991. Social Movements: The Politics of Moral Protest. London: Longmans.

PARRY, G, MOYSER, G e DAY, D. 1992. Political Participation and Democracy in Britain. Cambridge: Cambridge University Press.

ROWELL, Andrew. 1996. Green Backlash: Global Subversion of the Environmental Movement. London: Routledge.

SCOTT, Alan. 1990. Ideology and the New Social Movement. London: Unwin Hyman. 


\section{Resumo}

Os estudos sobre protesto e conflito no Reino Unido são dominados há décadas pelas pesquisas sobre o local de trabalho e as atividades sindicais. Nos anos 80 e 90, o declínio dos antigos setores industriais combinou-se com a crescente insegurança econômica e com a legislação governamental, causando um enfraquecimento das organizações de trabalhadores. A greve dos mineiros em 1984-1985 é vista como a última das grandes lutas dos sindicatos. Surgiram, contudo, novas formas de manifestação pública, de cunho ambiental, identificadas como legítimas formas de protesto, que acabaram por influenciar políticas governamentais, em particular no que concerne à crescente exploração de minas de carvão a céu aberto. Nas duas últimas décadas viu-se, assim, a mobilização de uma "nova classe", que veio a formar a espinha dorsal dos novos movimentos sociais e que trouxe questões específicas como a paz e o meio ambiente para o primeiro plano da vida política.

\section{Abstract}

For decades, studies of protest and conflict have been dominated by research into workplaces and union activities. In 1980s and 1990s Britain, the decline of the old industrial sectors combined with increasing economic insecurity and government legislation to create a weakening of workers' organizations. The 1984-85 miners' strike was seen as the last of the unions' great struggles. However, new forms of public demonstration appeared addressing environmental issues; these became identified as legitimate forms of protest and ended up influencing government policies, in particular those relating to the growing exploitation of open-seam coal mining. The last two decades have thus witnessed the mobilization of a 'new class' of people who form the backbone of the new social movements and who bring specific questions such as peace and the environment to the forefront of political life. 